mediated processes rather than being a core part of the cargo-transport mechanism. Further investigation of how $\mathrm{BicD}$ and $\mathrm{Egl}$ function at the molecular level in Drosophila will greatly aid in the search for functional Egl homologues in vertebrate cells.

1. Riechmann, V. \& Ephrussi, A. Curr. Opin. Genet. Dev. 11, 374-383 (2001)

2. Matanis, T. et al. Nature Cell Biol. 4, 986-992 (2002).

3. Navarro, C. et al. Nature Cell Biol. 6, 427-435 (2004).
4. Karcher, R. L. Deacon, S. W. \& Gelfand, V. I. Trends Cell Biol. 12, 21-27 (2002).

5. Bolivar, J. et al. Development 128, 1889-1897 (2001).

6. Mach, J. M. \& Lehmann, R. Genes Dev. 11, 423-435 (1997).

7. Swan, A. Nature Cell Biol. 1, 444-449 (1999).

8. Bullock, S. L. \& Ish-Horowicz, D. Nature 414, 611-616 (2001).

9. Huynh, J.-R. \& St Johnston, D. Development 127 , 2785-2794 (2000).

10. Roper, K. \& Brown, N. H. Curr. Biol. 14, 99-110 (2004).

11. Hoogenraad, C. C. et al. EMBO J. 20, 4041-4054
(2001).

12. Januschke, J. et al. Curr. Biol. 12, 1971-1981 (2002).

13. Duncan, J. E. \& Warrior, R. Curr. Biol. 12, 1982-1991 (2002).

14. Swan, A. \& Suter, B. Development 122, 3577-3586 (1996).

15. Mohler, J. \& Wieschaus, E. F. Genetics 112, 803-822 (1986).

16. Brendza, R. P. et al. Science 289, 2120-2122 (2000).

17. Gross, S. P. Curr. Biol. 13, R320-R322 (2003).

18. Hoogenraad, C. C. et al. EMBO J. 22, 6004-6015 (2003).

19. Schnorrer, F. Bohmann, K. \& Nüsslein-Volhard, C. Nature Cell Biol. 2, 185-190 (2000).

\section{Human disease: the centrosome connection}

Defects in cell-cycle progression and chromosome segregation are commonly associated with human disease phenotypes, most notably cancer. Propagating a stable genome through cell division requires the accurate segregation of a full complement of chromosomes to each daughter cell. Centrosomes are highly structured organelles that are critical for this process: they are found at the poles of mitotic spindles and at the base of cilia (specialized cellular structures derived from modified centrioles), where they are thought to function as microtubule-organizing centres. Kim et al. (Nature Genet. DOI: 10.1038/ng1352) now report a link between $\mathrm{PCM} 1$, a protein found in centriolar satellites, and a heritable disease called Bardet-Biedl syndrome (BBS).

Centrosomes consist of a pair of centrioles embedded in a proteinaceous pericentriolar matrix and are surrounded by poorly characterized sub-cellular structures termed 'centriolar satellites'. Early clues that BBS - a disease characterized by retinal degeneration, obesity, renal disorder and other defects - might result from malfunction of the pericentriolar material came from studies in Caenorhabditis elegans, and from analysis of mammalian gene expression and protein localization patterns for several of the eight known proteins linked to BBS (Ansley, S. J. Nature 425, 628;

2003). This idea was strengthened further by the phenotypic similarities between BBS and other diseases that result from aberrant function of cilia or basal bodies.

Kim et al. found that, as previously shown for BBS8, BBS4 also interacted with PCM1. This interaction was confirmed by several independent means, including yeast two-hybrid, coimmunoprecipitation and colocalization analyses. Similarly to PCM1, BBS4 localized to the centriolar satellites and to basal bodies. But what is the function of BBS4? Depletion of BBS4 by
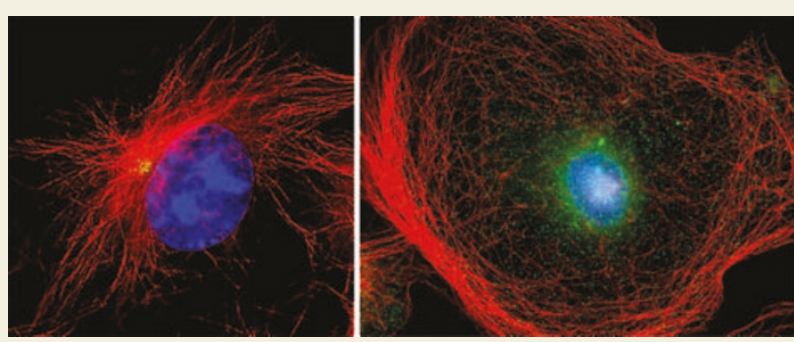

Ablation of BBS4 (right) results in dispersed $\mathrm{PCM}-1$ staining (green) and de-anchored microtubules (red). A wild-type cell (left) is also shown PCM-1 (yellow), microtubules (red).

RNA interference resulted in delocalization of PCM1 from the satellites, disorganized microtubule arrays through defective anchoring of microtubules, and an accumulation of multi-nucleate cells, indicating defects in cell division. The discovery of an interaction between BBS4 and a component of the microtubuledependent dynein-dynactin motor, p150glued, further suggested that it might be an adaptor for transporting cargo (for example,

PCM1) to its proper cellular destination.

The crucial question now is whether aberrant centrosome and basal-body function is at the heart of the defects associated with BBS. PCM 1 and BBS4 colocalize in specific cell types in tissues affected by the disease, and mutant BBS4 proteins similar to those found in patients delocalize PCM1 and disrupt microtubule organization. However, a formal demonstration that centrosomal and/or basal body malfunction accounts for any or all of the highly heterogenous pathologies of BBS awaits further study. Another question for the future concerns whether different BBS genes function in a co-ordinated manner to regulate one or more cellular processes.

SOWMYA SWAMINATHAN 